\section{THE DEMOGRAPHIC CHARACTERISTICS OF PATIENTS SEEKING HEALTH CARE FOR INFANT AND CHILDHOOD ILLNESSES AT NEPAL MEDICAL COLLEGE AND TECHNING HOSPITAL}

Kishore Raj Pandey* Phanindra Prasad Kafle Debendra Karki

Abstract: This paper presents the demographic characteristics of 424 patients and their parents/guardians over a four month period seeking health care for infant and childhood illnesses at Nepal Medical College and Teaching Hospital which is located at the outskirts of the Kathmandu Valley. The objective of the paper is to find out the health care of infant patients at Nepal Medical College. Out of a total of 424 patients seeking health care for infant and childhood illnesses over a four month long period at Nepal Medical College and Teaching Hospital, only 42 percent were females and the remaining 58 percent of the patients were males. Despite the fact that Nepal Medical College and Teaching Hospital is located in an area that is home to many of the large carpet factories located in the Kathmandu Valley which employ a lot of people that belong to various "tribal" and "ethnic" groups, the findings from the study point to the fact that almost half of the patients came from higher caste groups-mainly Brahmins and Chettris (214 out of 424 patients). Only 105 patients stated that they belonged to a Hill Tribal Group and another 36 patients stated that they belonged to a Terai Tribal Group. The most overlooked group consisted of

Authors are Associated with Nepal Medical College, Attarkhel, Kathmandu. the Dalit Group with only 10 patients. The overall school attendance rate of patients seeking health care services for infant and childhood illness as reported in this study appears to be very high. Only 8 patients out of 176 patients that were 6 years and older stated that they had never attended school so far. This points to the fact that the school attendance rate of patients that are seeking health care services for infant and childhood illness at Nepal Medical College and Teaching Hospital is quite high. This hospital-based study with very limited resources is a proof that very high quality research can be conducted that highlights many of the positive as well as negative aspects of health care services Nepal Medial College and Teaching Hospital has to offer. This study also points to the fact that various departments within the parent institution and professionals with different backgrounds and interests can conduct collaborative research.

Key words: Nepal Medical College and Teaching Hospital, health services, opportunity costs, infant and childhood illness, Kathmandu Valley.

\section{Introduction}

While there are numerous factors that contribute to infant and childhood illnesses, this paper outlines the demographic characteristics of patients seeking health care for infant and childhood illnesses at Nepal Medical College and Teaching Hospital (NMTCH). This paper presents the findings of a hospital-based study of 424 patients that came to seek health care for infant and childhood illnesses during a four month period (March-June, 1999) at the Out patient Department at Nepal Medical College and Teaching Hospital. Various factors affect the interval between the onset of the illness and its outcome. It is generally assumed that if prompt, and adequate treatment is provided, the outcome will usually be satisfactory, therefore, the outcome is most adversely affected by delayed treatment (Deborah,1994).

At the time this research activity was conducted, it had been only a little over a year since Nepal Medical College and Teaching Hospital had started to provide health care services in both its out patient department and hospital based services. This 
paper outlines the findings of one of the very first research activity that was carried out at the Nepal Medical College and Teaching Hospital. At the outset, it was decided that it was of paramount importance to both the department of pediatrics and department of community medicine to have sufficient empirical data on the demographic characteristics of the patients seeking health care for infant and childhood illness. These two departments would not be able to plan to expand services in the areas of immunization, counseling and maternal child health in absence of such data.

\section{Data and Methods}

The data used in this paper were collected as part of a larger study that sought to solicit information on the factors that affect the interval between the onset of the illness and the timing of arrival at NMCTH to seek health care to the parents/guardians of the children with illness. The research design employed a combination of survey questionnaires and "focused in-depth interviews" (Knodel, 1997) to analyse categorically the health seeking behaviour of infant and childhood illnesses at the NMCTH, On the outset it must be noted that infants and children do not seek health care on their own. Data was collected over a four months period (March-June, 1999) with a total of 424 parents/guardians that accompanied their infants and children to seek health care services at NMCTH. The "focused in-depth interviews" were conducted with the parents/guardians upon receiving their verbal "informed consent". Certain broad themes were developed prior to the study and pre-tested. Necessary interviews" were free flowing and lasted between 20 and 30 minutes. These "focused in depth interviews" were conducted by a trained nurse who has had many years of experience in health and social research.

Survey questionnaires were administered to all 424 parents and guardians that accompanied their infants and children to NMCTH. The survey questionnaires collected vital information of the following topics:

(1) demographic characteristics of the clients; actors involved in decision-making (father, mother, brothers, sisters, uncle, aunt, other relatives, etc);

(3) Costs, time and means of transportation used to travel to the NMCTH;

(4) distance travelled from home to NMCTH;

(5) financial and opportunity costs;

(6) previous experience with NMCTH; and

(7) their perceived quality of care at NMCTh.

The survey questionnaires were pre-coded and administered by the trained researchers. It must be noted here that information obtained through the survey questionnaires were complemented through "focused in-depth interviews." Furthermore, it was vital that the same trained person conducted both the qualitative and quantitative components of the research.

\section{Findings of the Research}

\subsection{Demographic Characteristics of Patients}

Out of a total of 424 infants and children seeking health care servies at Nepal Medical College and Teaching Hospital over a period of four months, data were collected from 180 female and 244 male patients

Table 1 presents the number and percentage according to caste/ethnicity of patients seeking health care for infant and childhood illnesses at Nepal Medical College and Teaching Hospital. A total of 424 infants and children received health care services during the four month long period of which the largest group were Brahmins $(\mathrm{N}=121)$ which were closely followed by Hill Tribals $(\mathrm{N}=105)$. It must be noted here that the smallest number of health care seekers during that time period were the Dalit Group $(\mathrm{N}=10)$.

\subsection{Living Arrangement of Patients}

Table 2 presents the number and percentage of patients stating that they live with their family members or have other living arrangements. Of the 424 patients, 411 stated that they live with their immediate family members. only 13 patients stated that they have other living arrangements. 


\subsection{Schooling of Patients}

Out of a total 176 patients were 6 years of age and older. Table 3 presents the level of schooling completed by patients 6 years and older and the number of patients enrolled at the preprimary level. When these 176 patients were asked about their level of schooling 8 stated they have received no schooling so far. 157 patients stated that they are currently attending or have enrolled at the Primary School (classes 1 through 5) level in the past. Similarly, another 11 patients stated that they are currently attending or have enrolled at the Lower Secondary School (classes 6 and 7) level in the past. Another 93 patients stated that thety were attending shcool at the Pre-primary level at the time of the interview.

Table 4 presents the number and percentage according to the type of school attended by 168 patients 6 years and above. A vast majority of them $(\mathrm{N}=136)$ stated that they attended a Private Bording School.

None of the patients stated that they attended a Religious School. Only 24 of the 168 students that were currently enrolled in any school stated that they attended a Government School.

\subsection{Occupation of the Person the Patient is Living with}

Table 5 presents the occupation of the person (in numbers and percentage) the patients is living with. A little less than half of the respondents $(\mathrm{N}=169)$ stated that they were either unemployed or underemployed. One hundred and seventeen respondents stated that they were employed in the private sector or the non-governmental sector. Another, 70 respondents stated that they were government employees. 40 respondents stated that they were self- employed and another 28 respondents stated that they were farmers.

\subsection{Employment Status of Patients}

Finally, Table 6 presents the number and percentage of patients 6 years and above who stated that they have worked for wages or were unemployed in the last one week. Out of 176 patients that were 6 years and above, 173, patients stated that they have remained unemployed in the last one-week. Only 3 patients stated that they worked for wages in the last one week.

\section{Conclusion}

First of all it must be noted that out of a total of 424 patients seeking health care for infant and childhood illnesses in a four month long period at Nepal Medical College and Teaching Hospital, only 42 percent $(\mathrm{N}=180)$ were females and the remaining 58 percent $(\mathrm{N}=244)$ of the patients were males. This finding points to the fact that Nepal Medical College and Teaching Hospital has not been successful in bring about "gender balance" as it provided health care to infants and children despite the fact that 50 percent of the infant and child population of Nepal consists of females. This finding also points to the fact that Nepal Medical College and Teaching Hospital must take extra efforts in the coming days and months to encourage parents and guardians to seek health care for both male and female children. Nepal Medical College and Teaching Hospital may need to take extra steps so as to encourage parents guardians to bring both their male and female children to seck health care services at Nepal Medical College and Teaching Hospital.

Despite the fact that Nepal Medical College and Teaching Hospital is located in an area that is home to many of the large carpet factories located in the Kathmandu Valley which employ a lot of people that belong to various "tribal" and ethnic" groups, the findings from the study point to the fact that almost half of the patients came from higher caste groups-mainly Brahmins and Chettris (214 out of 424 patients). Only 10 s patients stated that they belonged to a Hill Tribal Group and another 36 patients stated that they belonged to a Terai Tribal Group. The most overlooked group consisted of the Dalit Group with only 10 patients. Nepal Medical College and Teaching Hospital must work harder to attract patients from all strata of the Nepali society. So far, most of the patients belong to the higher caste groups- mainly Brahmins and Chettris.

The overall school attendance rate of patients seeking health care services for infant and childhood illness as reportes 
in this study appears to be very high. Only 8 patients out of 176 patients that were 6 years and older stated that they have never attended school so far. This points to the fact that the school attendance rate of patients that are seeking health care services for infant and childhood illness at Nepal Medical College and Teaching Hospital is quite high. It has already been pointed out in the section above that Nepal Medical College and Teaching Hospital is located in an area that is home to many large carpet factories that employ "migrant" population from various "tribal" and "ethnic" groups. From the findings of this study we are not able to say for sure if infants and children from these carpet factories are seeking health care services for infant and childhood illness at Nepal Medical College and Teaching Hospital. Various studies that have been reported by various non-governmental organizations highlight the fact that as much as 50 percent of school age children have never attended school.

Finally, this hospital-based study with very limited resources is proof that very high quality research can be conducted that highlights many of the positive as well as negative aspects of health care services Nepal Medical College and Teaching Hospital has to offer. This study also points to the fact that collaborative research can be conducted by various departments within the parent institution and professionals with different backgrounds and interests. The findings from this hospital-based research has also assisted both the Department of Pediatrics and Department of Community Medicine to develop new strategies to plan, develop and manage other services in the areas of child immunization, counselling and maternal child health.

Note:

(The authors would like to acknowledge the financial assistance provided by Nepal Medical College and Teaching Hospital to conduct this research. The services provided by Mrs Bimala Singh as Reserch Assistant and co-operation provided by Mrs Lalita Risal at the Department of Paediatrics and Ms. Sarita Joshi at the Department of Community Medicine were highly approciated.)

\section{REFERENCE}

Sereen Thaddeus and Maine, Deborah (1994). Too far to walk: Maternal mortality in contest, Social Science and Medicine 238 (8): 1091-1110

Knodel, John (1997). A case for non- anthropological qualitative methods for demographers. Population and Development

Tables

Table 1 Caste/ Ethnicity of Patients

\begin{tabular}{|l|l|l|}
\hline Caste/Ethnicity & N & $\%$ \\
\hline Brahmin & 121 & 28,5 \\
\hline Chettri & 93 & 21,9 \\
\hline Tarai Caste & 9 & 21 \\
\hline Hill Tribal Group & 107 & 24,8 \\
\hline Terai Tribal Group & 36 & 8,5 \\
\hline Dalit Group & 10 & 2,4 \\
\hline Others & 48 & 11,3 \\
\hline Total & 424 & 100 \\
\hline
\end{tabular}

Source : Hospital survey, 2002

Table 2: Number and Percentage of Patients Stating Tahat They Live With:

\begin{tabular}{|l|l|l|}
\hline Category & N & $\%$ \\
\hline Self with Family & 411 & 96,9 \\
\hline Have Other Living Arrangemnt & 13 & 3,1 \\
\hline Total & 424 & 100 \\
\hline
\end{tabular}

Source : Source : Hospital survey, 2002

Table 3 : Level of School Completed By Patients 6 Years and Older

\begin{tabular}{|l|l|l|}
\hline Level of Schooling & N & $\%$ \\
\hline No Schooling & 8 & 4,5 \\
\hline Primary(1-5) & 157 & 89,2 \\
\hline Lower Secondary(6-7) & 11 & 6,3 \\
\hline Total & 176 & 100 \\
\hline $\begin{array}{l}\text { No. of Patients Attending School at } \\
\text { the Pre-Primary Level }\end{array}$ & 99 & N/A \\
\hline
\end{tabular}


Source : Source : Hospital survey, 2002

Table 4 : Type of School Attended by Patients, Number and Percentage

\begin{tabular}{|l|l|l|}
\hline Type of School & N & $\%$ \\
\hline Government School & 24 & 14,29 \\
\hline Private Day School & 7 & 4,17 \\
\hline Private Boarding School & 136 & 80,95 \\
\hline Other, Specify & 1 & 0,60 \\
\hline Total & 168 & 100,00 \\
\hline
\end{tabular}

Source : Source : Hospital survey, 2002

Note: Only 186 of the 424 patients were 6 years and older

Table 5; Occupation of the Person the patient is Living with, Number and Percentage

\begin{tabular}{|l|l|l|}
\hline Patient's Guardian's occupation & No. & $\%$ \\
\hline Government Employee & 70 & 16,51 \\
\hline Private sector/INGO/NGO employee & 117 & 27,59 \\
\hline Self Employed & 40 & 9,43 \\
\hline Farmer & 28 & 6,60 \\
\hline Employed & 1 & 0,24 \\
\hline Other, Specify & 168 & 39,62 \\
\hline Total & 424 & 100,00 \\
\hline
\end{tabular}

Source: NMC Hospital Based Study

Table 6: Number and Percentage of Patients Who Stated That They were Employed or Unemployed in the last one week

\begin{tabular}{|l|l|}
\hline Situation & N \\
\hline Worked for Wages & 3 \\
\hline Have not worked for wages & 173 \\
\hline Total & 176 \\
\hline
\end{tabular}

Source: NMC Hospital Based Study

Note: Out of a total of 424 patients and/or parents interviewed, 176 responded to this question. This is due to the very low ages of the remaining patients.

\section{AN OBITUARY TO PROF. GS. NEPALI}

Ganesh Man Gurung*

"I will never forget that cold Kathmandu morning in January 1994, when Madam Lajja offered me a cup of tea. At that point, Prof. Nepali mixed a spoon of khukuri rum in my black tea. Not only was taste quite different, and cheery on a chilly morning - the man himself was a unique individual, cheerful and jolly with his many friends and colleagues."

Today the Department of Sociology has lost a renowned professor, an amiable colleague and a knowledgeable scholar, a man well known in Nepal and abroad. Especially noteworthy is this scholarly achievement fin his book, "The Newars".

For 10 years, Prof. Nepali taught in our department will zeal and enthusiasm, after his retirement from Benaras Hindu University. I always found him alert, enthusiastic, energetic and interested in his teaching work. He was well respected by colleagues and the administrative staff of the department, and revered by his students. Despite his age, he rarely missed a class and was always attentive of his duties. He was equally popular among professors and scholars of Nepal and abroad, due to his open-hearted cooperation to all. He was always smiling and jolly with colleagues and juniors. However, among the professors in Kirtipur, he especially loved to conduct lengthy discussions with

Prof. Ganesh Man Gurung worked for Central Department of Sociology/Anthropology in Tribhuvan University for more than twenty years. He is now an honorable member of Public Service Commission, HMG, Nepal. 